\title{
The impact of genital warts: loss of quality of life and cost of treatment in eight sexual health clinics in the UK
}

\author{
S C Woodhall, ${ }^{1}{ }^{1} 2 \mathrm{M} \mathrm{Jit},{ }^{2} \mathrm{~K}$ Soldan, ${ }^{2} \mathrm{G}$ Kinghorn, ${ }^{3} \mathrm{R}$ Gilson, ${ }^{4} \mathrm{M}$ Nathan, ${ }^{5} \mathrm{~J} \mathrm{D}$ Ross, ${ }^{6}$ \\ C J N Lacey, ${ }^{1}$ on behalf of the QOLIGEN study group
}

\begin{abstract}
- A supplementary technical appendix is published online only. To view this file please visit the journal online (http://sti. bmj.com)

${ }^{1}$ Hull York Medical School, University of York, York, UK ${ }^{2}$ Health Protection Agency, London, UK

${ }^{3}$ Department of Genitourinary Medicine, Royal Hallamshire

Hospital, Sheffield, UK

${ }^{4}$ Research Department of Infection and Population Health, Centre for Sexual Health and HIV Research, University College London, and Camden Provider Services, London, UK

${ }^{5}$ Department of Sexual Health, Homerton University Hospital,

London, UK

${ }^{6}$ Whittall Street Clinic

Birmingham, UK
\end{abstract}

\section{Correspondence to}

S C Woodhall, Health Protection Agency, 61 Colindale Avenue. London, NW9 5E0, UK; sarah.woodhall@hpa.org.uk

Accepted 9 April 2011

Published Online First

2 June 2011

\section{(2) UNLOCK:}

This paper is freely available online under the BMJ Journals unlocked scheme, see http://sti. bmi.com/site/about/unlocked. xhtml

\section{ABSTRACT}

Objectives To estimate the loss of quality of life and cost of treatment associated with genital warts seen in sexual health clinics.

Methods A cross-sectional questionnaire study and case note review of individuals with genital warts, carried out in eight sexual health clinics in England and Northern Ireland. Individuals with genital warts attending the participating clinics were invited to take part in the questionnaire study. 895 participants were recruited. A separate sample of 370 participants who had attended a participating clinic with a first visit for a first or recurrent episode of genital warts between April and June 2007 was included in the case note review. Quality of life was measured using the E0-5D questionnaire and the cost of an episode of care was derived from the case note review.

Results The weighted mean EQ-5D index score was 0.87 (95\% $\mathrm{Cl} 0.85$ to 0.89 ). The weighted mean disutility was 0.056 (95\% Cl 0.038 to 0.074). The estimated mean loss of quality-adjusted life-years associated with an episode of genital warts was $0.018(95 \% \mathrm{Cl} 0.0079$ to 0.031 ), equivalent to 6.6 days of healthy life lost per episode. The weighted mean cost per episode of care was $£ 94$ (95\% Cl £84 to £104), not including the cost of a sexually transmitted infection screen.

Conclusions Genital warts have a substantial impact on the health service and the individual. This information can be utilised for economic evaluation of human papillomavirus vaccination.

Human papillomavirus (HPV) vaccination is available free at the point of delivery through the national vaccination programme in England, which offers school-based HPV vaccination routinely to 12-13-year-old girls. Scotland, Wales and Northern Ireland offer equivalent vaccination programmes. Two vaccines are licensed for use in the UK, a bivalent (Cervarix) and a quadrivalent (Gardasil).

The choice of vaccine to include in the national programme was made following a competitive tendering process ${ }^{1}$ informed by an economic evaluation. ${ }^{2}$ Information about the impact of genital warts was a key determinant of the relative cost effectiveness of the two available HPV vaccines, as whereas both vaccines protect against HPV 16 and 18 , which cause the majority of cases of cervical cancer, ${ }^{3}{ }^{4}$ only the quadrivalent vaccine offers protection against HPV 6 and $11,{ }^{5}$ the cause of most genital warts. ${ }^{6}$

The impact of genital warts on the health service is substantial, with approximately 125000 episodes of genital warts diagnosed in sexual health clinics in England in 2009.? Treatment consists of clinicbased ablative treatments, pharmaceutical therapies administered by the patient at home, or a combination of these approaches. Cases may require repeated treatments before clearance of the lesion(s), and recurrence rates following treatment of between $10 \%$ and $40 \%$ have been reported in clinical trials. ${ }^{8}$ The majority of cases in England are treated in sexual health clinics, although some are treated in primary care and a small proportion require referral to hospital for surgical removal. ${ }^{9}$

The widespread use of the quadrivalent HPV vaccine has been reported to have a large effect on the incidence of genital warts. ${ }^{10-12}$ The potential benefits in terms of quality of life and costs saved should be included when comparing cost effectiveness of HPV vaccines and vaccination strategies. The costs and quality of life loss from a single centre study have previously been used in economic evaluation of HPV vaccination. ${ }^{13} 14$ Given remaining questions about the value of vaccination against genital warts, ${ }^{1} 1516$ we carried out a multicentre study to provide estimates of quality of life loss and cost per episode of care for use in further economic evaluations of HPV vaccination.

\section{METHODS}

The study was carried out in a convenience sample of seven sexual health clinics in England (Birmingham, Cambridge, Harrogate, Homerton and the Mortimer Market Centre in London, Sheffield and York) and one in Northern Ireland (Belfast). The sites were chosen to be a mix of urban and semi-urban clinics and had varying sizes of patient population. The Homerton clinic also provided specialist laser treatment for severe cases of warts referred from other centres.

The study was conducted in two parts: a questionnaire was used to collect information about quality of life and consultation time, and a case note review was used to collect costs of treatment and the duration of an episode of care.

\section{Questionnaire study}

Patients aged 16 years or over attending the participating centres during the recruitment period with a current diagnosis of genital warts were invited to complete a questionnaire during their clinic visit, consisting of demographic and behavioural questions and questions about the participant's genital warts history. Data collection took 
place between August 2009 and February 2010. Each clinic recruited for at least 3 months.

The questionnaire included the EQ-5D, which is a short, standardised generic questionnaire to measure health-related quality of life. ${ }^{17}$ The EQ-5D requires respondents to state whether they have no, some, or extreme problems in relation to five dimensions of their health (mobility, usual activities, selfcare, pain or discomfort and anxiety or depression). Combinations of answers to these questions are mapped to health states with index scores from 0 to 1 according to preference weights applied from a general population sample. ${ }^{18}$ The EQ-5D also includes a visual analogue scale (EQ-VAS), in which respondents are asked to rate their current state of health on a scale of $0-100$. The attending staff members noted the consultation duration and treatment provided on an accompanying questionnaire.

EQ-5D scores for each participant were compared with age group and sex-matched average scores from the standard UK reference population (UK population norms). ${ }^{19}$ Disutility was defined as the difference between the study population and UK population norms on the EQ-5D index.

Time from onset until attendance was calculated for participants attending for a first visit of the first episode only, as it appeared that participants with recurrent episodes often reported the start of their first episode, rather than the onset of symptoms for the current one. Participants from the Homerton clinic were excluded from this analysis due to the high proportion of referrals from other sexually transmitted infection (STI) clinics at this site.

Participants who gave consent for follow-up were sent a second questionnaire 2 weeks after their baseline visit, either by post or email.

\section{Case note review}

Sequential individuals attending for a first visit of either a first or recurrent episode between April and June 2007 were selected for the case note review. The data collection period ended on 31 August 2009; thus each patient had a minimum of 2 years of potential follow-up time available. Each individual contributed one episode of care (defined as the period between the first and last clinic visit for that occurrence of warts).

Details of the treatments received and the staff members involved at each visit of the study episode of genital warts were collected. Costing was carried out from a health service perspective. Unit costs for staff ${ }^{20}$ and treatments were applied to estimate the cost per episode of care (table 1). Site-specific average consultation times for genital warts collected prospectively as part of the questionnaire study were used (see supplementary technical appendix, available online only). All costs were calculated as 2010 pounds sterling. No discount rate was applied as the costs of genital warts treatment were incurred within 12 months in $98 \%$ of cases. It is standard practice to test patients attending sexual health services for other STI including HIV. ${ }^{24}$ However, economic evaluations of vaccination have not previously taken into account the potential benefits of such screens (ie, detection of an undiagnosed infection). Therefore costs per episode are presented here both with and without the cost of an STI screen (£52.12 per person, estimated from a previous study, ${ }^{23}$ comprising laboratory costs for chlamydia and gonorrhoea nucleic acid amplification tests, syphilis and HIV tests).

\section{Loss of quality-adjusted life-years}

Quality of life was assumed to decrease linearly from the level of the UK population norm to the level measured in the study
Table 1 Unit costs*

\begin{tabular}{|c|c|c|}
\hline Item & Cost per use & Source \\
\hline Podophyllotoxin cream & $£ 14.86$ & 21 \\
\hline Podophyllotoxin solution & $£ 12.38$ & 22 \\
\hline Imiquimod & $£ 51.32$ & 21 \\
\hline Cryotherapy & $£ 4.27$ & Clinic costing \\
\hline Trichloroacetic acid & $£ 0.32$ & Clinic costing \\
\hline Podophyllin & $£ 0.02$ & 21 \\
\hline EMLA cream & $£ 1.73$ & 22 \\
\hline Hyfrecation & $£ 5.63$ & Clinic costing \\
\hline Curettage & $£ 4.66$ & Clinic costing \\
\hline Diode laser & $£ 143.50$ & Clinic costing \\
\hline $\mathrm{CO}_{2}$ laser & $£ 125.49$ & Clinic costing \\
\hline STI screen $\dagger$ & $£ 52.12$ & 23 \\
\hline \multicolumn{3}{|c|}{$\begin{array}{l}\text { *Costs per use include equipment, consumables and pharmaceuticals } \\
\text { plus tax (17.5\%) when applicable. A detailed breakdown of the items } \\
\text { included for each cost is provided in the supplementary technical } \\
\text { appendix (available online only). } \\
\text { †lncludes testing for chlamydia, gonorrhoea, syphilis and HIV. } \\
\mathrm{CO}_{2} \text {, carbon dioxide; EMLA, eutectic mixture of local anaesthetic; STI, } \\
\text { sexually transmitted infection. }\end{array}$} \\
\hline
\end{tabular}

between noticing warts and the start of an episode of care, and then remain at the measured level until the end of the episode of care (at the last clinic visit for that wart episode). In the base case, quality of life was assumed to remain at this level for the duration of any prescription for home treatment (28 days) ${ }^{22}$ received at the last visit. When only clinic treatment had been used at the last visit of the episode of care, quality of life was assumed to remain constant for a recovery period, estimated based on the opinion of the clinical investigators as 14-42 days, depending on treatment. Previous studies have found that quality of life can be affected after the clearance of warts, ${ }^{25} 26$ although reliable estimates for the duration of any continued detriment are not available in the literature. In order to make allowance for some continuing quality of life loss at the end of the episode, quality of life was assumed to return to the UK population norm linearly over 2 weeks. We varied our assumptions (by including or excluding the additional assumed durations following the episode of care) in sensitivity analyses.

\section{Sample size and statistical analysis}

A target sample size of 230 was determined to be sufficient to detect a difference of 0.04 on the EQ-5D index between individuals recruited with genital warts and population controls. For the case note review, we aimed to review 40 (20 male, 20 female) case notes per site.

Sampling weights were applied to allow for differential recruitment from each clinic and to standardise estimates to the age and sex distribution of patients aged 16-64 years attending sexual health clinics in England in 2009 with a diagnosis of genital warts. ${ }^{27}$ In the case note review, observations from patients receiving laser treatment were also weighted to prevent overestimation of costs and duration associated with this specialist treatment. Non-parametric tests of significance were used to compare quality of life and cost per episode of care between centres and subgroups. Data on duration and disutility were obtained from two different sources (the retrospective case note review and the questionnaire survey). We combined the two sets of data to construct a simulated dataset in order to estimate mean quality-adjusted life-year (OALY) loss and CI. Bootstrapped CI were estimated from repeated constructions of the simulated dataset (see supplementary technical appendix, available online only). 
Table 2 Characteristics of participants in the questionnaire study

\begin{tabular}{llll}
\hline & $\begin{array}{l}\text { Male } \\
\mathbf{n}=\mathbf{4 9 4}\end{array}$ & $\begin{array}{l}\text { Female } \\
\mathbf{n}=\mathbf{4 0 0}\end{array}$ & $\begin{array}{l}\text { All } \\
\mathbf{n}=\mathbf{8 9 5}\end{array}$ \\
\hline Age, years & & & \\
Mean & 30 & 25 & 28 \\
Range (min-max) & $17-60$ & $16-73$ & $16-73$ \\
Visit type & & & \\
First & $51 \%(245)$ & $53 \%(204)$ & $52 \%(449)$ \\
Follow-up & $49 \%(232)$ & $47 \%(183)$ & $48 \%(415)$ \\
First or recurrent episode & & & \\
First & $61 \%(302)$ & $71 \%(284)$ & $65 \%(586)$ \\
Recurrent & $39 \%(192)$ & $29 \%(116)$ & $35 \%(309)$ \\
Number of previous episodes & & & \\
None & $61 \%(302)$ & $71 \%(284)$ & $65 \%(586)$ \\
One & $23 \%(114)$ & $19 \%(76)$ & $21 \%(191)$ \\
More than one & $16 \%(78)$ & $10 \%(40)$ & $13 \%(118)$ \\
Treatment at baseline visit & & & \\
Home treatment & $17 \%(84)$ & $19 \%(75)$ & $18 \%(159)$ \\
Clinic treatment & $49 \%(237)$ & $52 \%(203)$ & $50 \%(440)$ \\
Both & $27 \%(131)$ & $21 \%(83)$ & $24 \%(214)$ \\
None & $7 \%(32)$ & $8 \%(30)$ & $7 \%(62)$ \\
Sexual orientation (patient reported) & & \\
Heterosexual & $83 \%(408)$ & $98 \%(391)$ & $90 \%(791)$ \\
Homosexual or bisexual & $17 \%(84)$ & $2 \%(8)$ & $10 \%(92)$ \\
Attendance at GP clinic or other SH clinic for this & episode of GW* \\
GP & $38 \%(114)$ & $47 \%(134)$ & $42 \%(248)$ \\
Other SH clinic & $16 \%(49)$ & $15 \%(44)$ & $16 \%(93)$ \\
None & $51 \%(153)$ & $42 \%(119)$ & $46 \%(272)$ \\
\hline$*$ *aticipars &
\end{tabular}

*Participants reporting attendance with first episode only.

$\mathrm{GP}$, general practitioner; GW, genital warts; SH, sexual health.

Completion of the questionnaire was considered as consent for participation in the questionnaire study. Consent was not obtained from individuals in the case note review; data collection was conducted by the local clinical team who sent anonymised data to the central study coordinator for analysis. The study was approved by the South Humber research ethics committee.

\section{RESULTS}

\section{Questionnaire study}

Eight hundred and ninety-five participants were recruited into the questionnaire study (table 2 ). The majority $(65 \%)$ of participants were attending with a first episode of genital warts and $42 \%$ of participants attending with a first episode of warts had previously attended their general practitioner to seek advice or treatment. The weighted mean time from the onset of lesions to attendance was 111 days (table 3 ).

The weighted mean EQ-5D index score was 0.87 , and the weighted mean EQ-VAS score was 77 (table 3). The weighted mean disutility was 0.056 . Disutility was larger (indicating a greater loss of quality of life) in women (0.063) than men (0.043) $\quad(p<0.0001)$. No significant difference was observed between first or recurrent episodes, but disutility did differ by age group ( $p=0.0001)$, with the highest loss of quality of life seen in 16-19-year-old women and 35-44-year-old men (figure 1).

The majority of the detriment to quality of life was registered on the pain and anxiety domains of the EQ-5D, with $37 \%$ of participants indicating they had moderate or extreme problems with anxiety or depression and $26 \%$ with pain or discomfort.

Four hundred and thirty-seven out of 895 participants consented to follow-up, of which 142 (32\%, 16\% overall) completed a follow-up questionnaire (68 men, 74 women). The mean time between baseline and follow-up was 31 days. Eighty-seven (61\%) participants reported that they still had warts at follow-up; $20 \%$ (17/84) of participants who still had genital warts had improved EQ-5D index scores at follow-up, as $\operatorname{did} 32 \%(17 / 53)$ of those whose warts had cleared, although the difference between these groups was not statistically significant $(p=0.12)$.

\section{Case note review}

Three hundred and seventy participants were included in the case note review (table 4). Patients in the review attended for a mean of 2.5 visits per episode of care. After applying sampling weights, an episode of care lasted for a mean of 36 days (95\% CI 27 to 46) (table 3). The duration and number of visits was highly skewed, with $55 \%$ of men and $45 \%$ of women attending for only one visit.

The weighted mean cost per episode of care was $£ 94$ (95\% CI $£ 84$ to £104) excluding the STI screen (table 3). There was significant variation in cost per episode of care between recruiting centres $(p=0.0004$, excluding laser patients) with the cost for non-laser patients ranging from $£ 86$ to $£ 137$ (figure 2). The mean cost per episode of care for patients receiving laser treatments was $£ 588$.

Table 3 Mean $(95 \% \mathrm{Cl})$ estimates of quality of life, duration of episode, cost of episode of care and QALY loss*

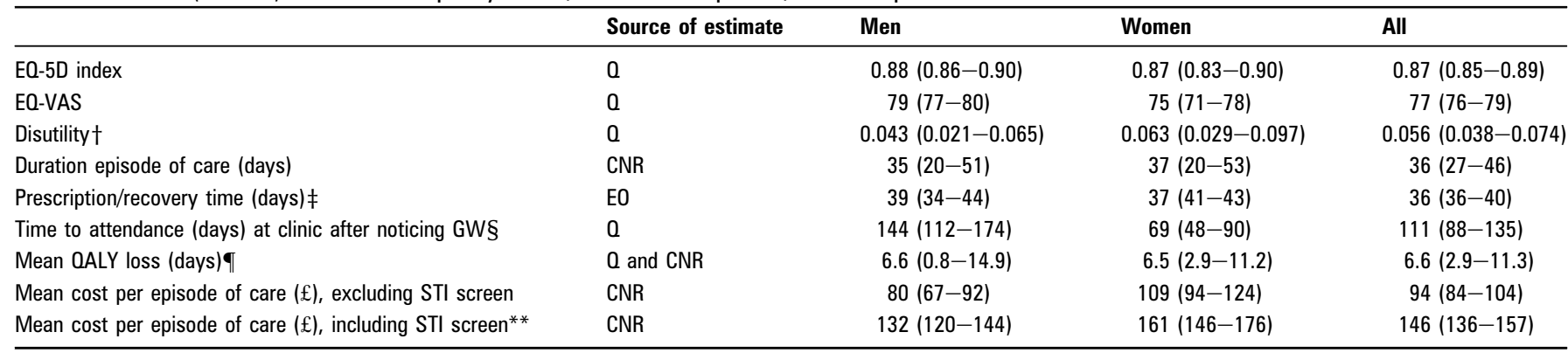

\footnotetext{
*Sampling weights applied.

†Loss of quality of life compared with UK population norms, as measured using the EQ-5D index

\#For analysis of quality-adjusted life-year loss, additional time after the end of an episode of care was included, to allow for continued presences of genital warts after the last clinic visit. When a prescription for home treatment was provided at the last visit, 28 days was added. When a clinic treatment was provided, 14-42 days was added as a reasonable recovery time (estimated based on prescription duration and clinical opinion). A further 14 days were added at the end of the episode to allow quality of life to return to the population norm.

$\S n=292$, based on participants reporting attendance with first visit of first episode only. One patient who reported a warts episode of 23 years was excluded. Patients from the Homerton clinic were also excluded, due to the large proportion of referrals from other centres. When participants provided a range the mid-point was taken to estimate the duration between a patient first noticing their warts and completing the questionnaire. Sampling weights applied to mean estimates.

qCalculated by combining disutility estimates and duration between onset of warts and attendance at clinic from the questionnaire study with duration of an episode of care plus an allowance for treatment and recovery.

${ }^{* *} £ 52.12$ per person, comprising laboratory processing costs of chlamydia, gonorrhoea, syphilis and HIV tests from a previous study. ${ }^{23}$

CNR, case note review; EO, expert opinion/literature; GW, genital warts; Q, questionnaire; QALY, quality-adjusted life-year; STI, sexually transmitted infection; VAS, visual analogue scale.
} 
Figure 1 Difference in EQ-5D index score by age and sex. ${ }^{*}$ Sampling weights applied.

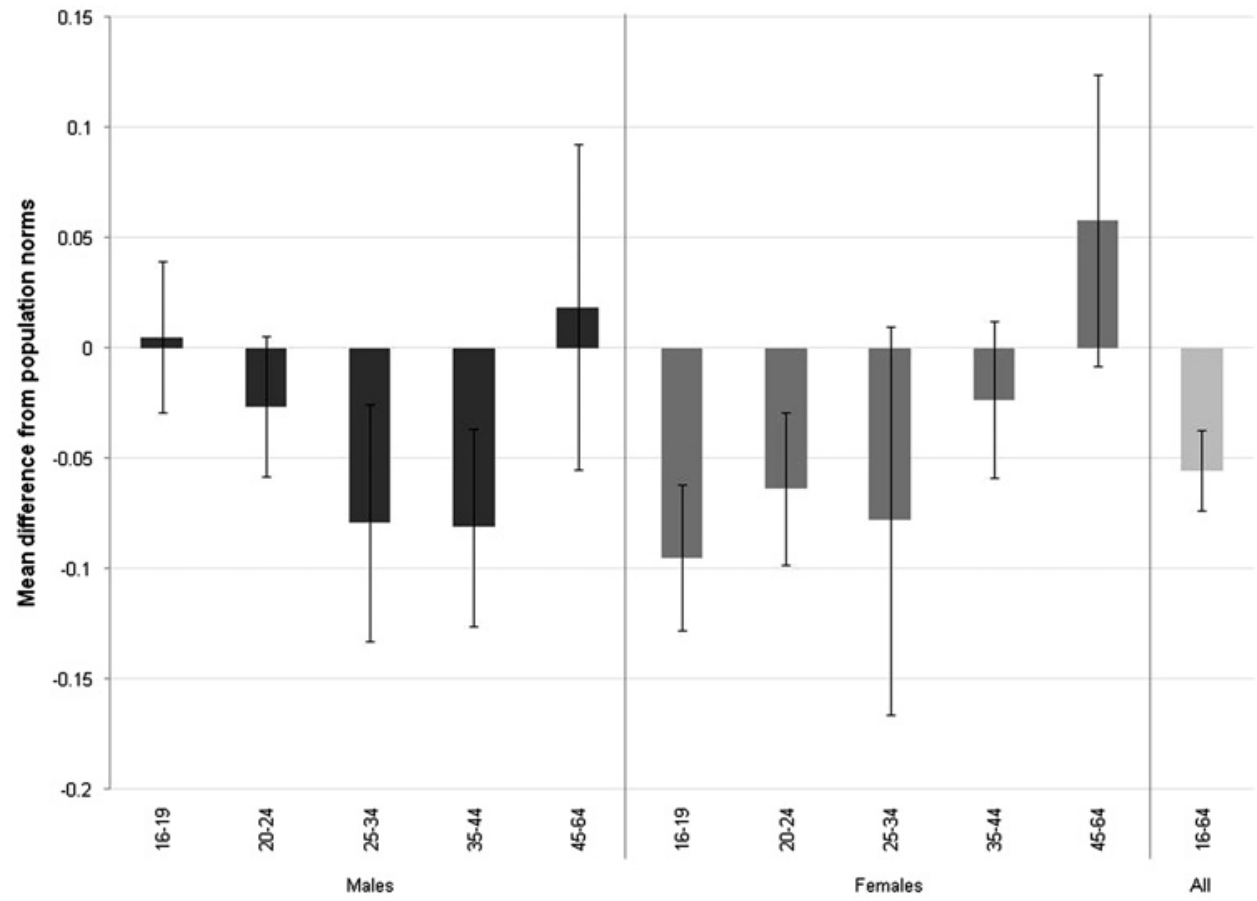

Age group (years) and sex

\section{OALY loss}

The overall weighted mean loss of OALY associated with an episode of genital warts for 16-64-year-olds in our base case analysis was 0.018 , equivalent to 6.6 days (95\% CI 2.9 to 11.3 ) of healthy life lost per episode (table 3 ).

In sensitivity analyses, the lower estimate scenario (using the pre-episode and the episode of care durations only) resulted in a mean OALY loss equivalent to 4.9 days (95\% CI 1.6 to 9.5 ).

\section{DISCUSSION}

In this multicentre study we estimated that an episode of genital warts is associated with a OALY loss equivalent to 6.6 days of healthy life lost. The cost of treatment per episode of care in a sexual health clinic was estimated at $£ 94$ (excluding STI screen). Our results demonstrate that genital warts present a substantial impact on the health service and the individual.

This is the largest study of quality of life loss associated with genital warts and provides the most detailed assessment of current treatment costs in the UK. In contrast to some previous studies, our results are based on responses from patients with direct current experience of genital warts rather than expert opinion or recall of previous episodes. ${ }^{28-30}$ Despite these strengths, this study has some limitations. First, the questionnaire study may have been subject to participation bias. Data on individuals who were not invited into the study, or who declined

Table 4 Characteristics of participants in the case note review

\begin{tabular}{llll}
\hline & $\begin{array}{l}\text { Male } \\
\mathbf{n = 2 1 3}\end{array}$ & $\begin{array}{l}\text { Female } \\
\mathbf{n = 1 5 7}\end{array}$ & $\begin{array}{l}\text { All } \\
\mathbf{n = 3 7 0}\end{array}$ \\
\hline $\begin{array}{l}\text { Age } \\
\text { Mean }\end{array}$ & 30 & 25 & \\
Range (min-max) & $(16-77)$ & $(15-57)$ & 28 \\
$\begin{array}{l}\text { First or recurrent episode } \\
\text { First }\end{array}$ & $66 \%(140)$ & $73 \%(114)$ & $69 \%(254)$ \\
Recurrent & $34 \%(73)$ & $27 \%(43)$ & $31 \%(116)$ \\
\hline
\end{tabular}

an invitation to take part were not recorded accurately at all sites. The participation rate and bias is therefore not known. However, participants in the questionnaire and case note review were comparable in terms of age and episode type, suggesting the questionnaire participants were broadly representative of clinic attendees with respect to these variables.

Second, it is not possible to confirm a causal relationship between the observed disutility and the presence of genital warts. Our results support the hypothesis of a causal association as most of the disutility was registered in the anxiety/depression scale and the pain/discomfort scale, which is consistent with the nature of genital warts. In addition, a trend for increased quality of life after clearance was observed at follow-up, although this was not significant and the low response rate makes these results difficult to interpret.

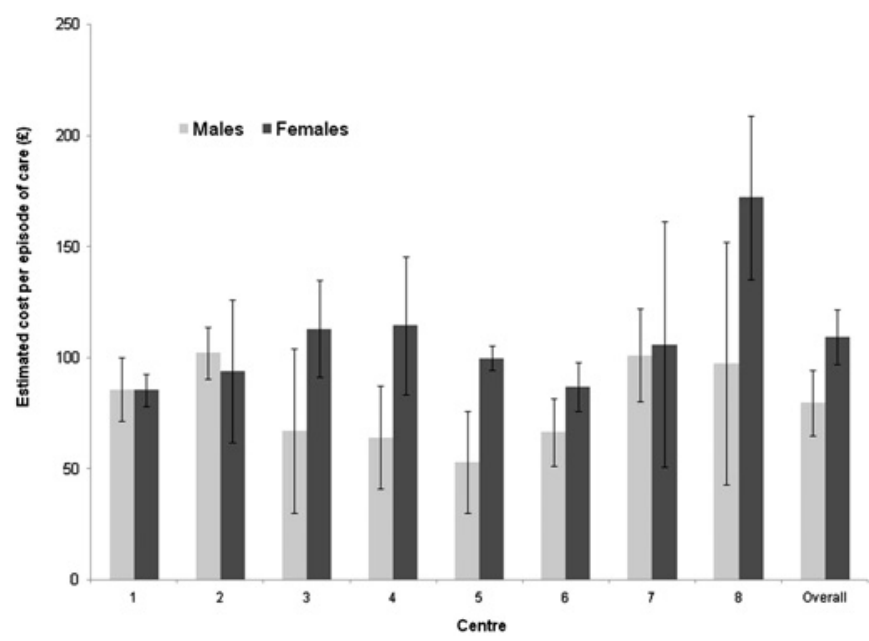

Figure 2 Mean cost per episode of care (excluding STI screen) by centre.* ${ }^{*}$ Sampling weights applied. Error bars show 95\% Cl. Patients receiving laser treatment at the Homerton are excluded from that centre's cost estimate, for purpose of the comparison of usual care. 
Our estimate of OALY loss is limited by the available information on duration of warts and how long quality of life is affected after the end of an episode of care. We did not collect information about the duration with warts after a last visit as part of this study, but it is feasible that concern over possible future recurrence and future transmission to new partners ${ }^{13}$ would result in an ongoing disutility for a substantial period after completion of an episode. Indeed, one previous study suggested that quality of life was affected several months after clearance. ${ }^{25}$ We applied assumptions about remaining impact on quality of life based on treatment and clinical opinion. However, our estimate may be a conservative one in the absence of further data. Winer et $a l^{31}$ reported a median duration of warts of 5.9 months in a cohort of female university students. This is comparable with our estimates of duration when the time between noticing warts and attending clinic, and the duration of the episode of care and allowances for treatment and recovery times were combined (mean 174 days; 5.7 months).

We have previously reported cost per episode and quality of life findings based on a similar study in a single sexual health clinic in England. ${ }^{13} 14$ We improved on our previous methodology by collecting data from several centres, thus increasing the precision and generalisability of our results. We also collected information on the time with genital warts before attending the clinic and data on the time taken for a visit to estimate staff costs per visit more accurately.

Previous studies of treatment costs for genital warts have reported a wide range of costs per episode, reflecting substantial differences in study methodologies, healthcare settings and treatment patterns. For example, in the UK, Brown et al ${ }^{29}$ reported a cost of $£ 170$ (2003 prices), but the authors used clinician reports to determine treatment methods rather than clinical data. Dee et al ${ }^{32}$ have reported a cost of $£ 287$ (2007 prices, Ireland), but this was based on a different costing approach, whereby overall clinic costs were divided by the proportion of clinic time required for warts. Langley et $a b^{33}$ reported a cost of $£ 117$ for men and $£ 104$ for women, based on a case note review carried out in 2000. Costs per episode of $£ 120$ (2006 prices, Canada), ${ }^{34} £ 158$ for men and $£ 243$ for women (2009 prices, Australia), ${ }^{35} £ 276$ (2002 prices, USA), ${ }^{36} £ 293$ (2005 prices, France) ${ }^{37}$ and $£ 287$ (2007 prices, Ireland) ${ }^{32}$ have been reported (exchange rates as at February 2011). Direct comparison between these estimates should, however, be undertaken with care. As shown by the variation between clinics, treatment costs varied substantially by setting even within our study. Large variation in treatment patterns has previously been observed ${ }^{33}$ and differences in terms of qualification and grade of attending clinical staff, time spent with the patient and the therapy of choice all contribute to the variation seen in cost per episode of care between centres. While we used local measurements of time taken for a visit when possible, further local variation in costs of overheads or the STI screen may not have been fully captured as standard costings were applied.

Our estimates of disutility and OALY loss are at the lower end of estimated ranges from two other studies using the EQ-5D carried out in the UK (disutility among 18-25-year-olds of 0.05 for men and 0.11 for women) ${ }^{38} 39$ and Canada (disutility of $0.08-0.23$ and OALY loss equivalent to 9-40 days of healthy life lost per episode). ${ }^{40}$

Differences in the age distribution of the study populations and different study methods offer possible explanations for the lower estimates seen in our results.

As with our previous study, young women appeared to be the most affected by having genital warts. ${ }^{13}$ This is in contrast to

\section{Key messages}

Estimates of treatment costs and impact on quality of life of genital warts are needed for economic evaluations comparing HPV vaccinations and vaccination strategies.

- This multicentre study found that each episode of genital warts was associated with a QALY loss equivalent to 6.6 days of healthy life lost.

- The cost of treatment per episode of care in a sexual health clinic was estimated at $£ 94$ (excluding costs of STI screening).

16-19-year-old men, who appeared not to have significant loss of quality of life compared with population norms. This difference may be due to differences in the stigma associated with STI between men and women; however, additional investigation would be needed to investigate this difference further.

Our results are based on a detailed costing of time and resources for a specific condition. Clinic payment in England is based on agreed 'tariff costs' from commissioners to providers. These payments ( $£ 133$ per single-professional first visit, £171 per multi-professional first visit, £101 per follow-up visit, 2010/11 genitourinary medicine tariffs ${ }^{41}$ are not split according to condition or treatment and they include direct overheads (utilities, management costs), which were not included in our estimates. The tariff payments for an episode of genital warts would therefore sum to more than our estimated costs.

We have presented information on quality of life losses in patients with genital warts attending sexual health clinics, and the resources used to treat them. To assess the total population impact of genital warts, these data should be considered together with the numbers of patients seen, and care given, in general practice and cases referred to other hospital care including surgery. It may be reasonable to assume that the average disutility will be similar in patients attending their general practitioner to those attending sexual health clinics, but the disutility would be expected to be larger in the small proportion of patients requiring other hospitalbased treatment. The cost of care is different in all three settings. ${ }^{9}$ Future economic evaluations of HPV vaccination will be able to utilise our results to compare the cost effectiveness of bivalent versus quadrivalent HPV vaccination in the UK more accurately.

Acknowledgements The authors thank all participants and staff at the recruiting clinics, along with members of the QOLIGEN (Quality of Life in patients with Genital Warts) Study Group and local collaborators, including Dr Christopher Sonnex, Dr Raymond Maw, Dr lan Fairley, Nadi Gupta, Patricia Gough, Alan Talaro, Ellie King, Lewis Lau, Sinead McKernan, Rebecca Faville, Jan Harding, Julia Burdett, Nicola Hickey and Dr Nicola Smith. We also thank Tom Nichols and Andrew Grant for providing statistical support.

Funding The study was funded by a grant to the HPA from the Department of Health Policy Research programme (039/0030). The views expressed are not necessarily those of the department. The authors' work was independent of the funders, who had no role in the design, collection, analysis or interpretation of the data, or in the decision to submit the article for publication.

Competing interests CJNL and JDR have received travel/accommodation costs from GlaxoSmithKline (GSK) and Sanofi Pasteur MSD (SPMSD); MN has received payment from GSK for delivering a lecture and associated travel; JDR has received payment from GSK and SPMSD for delivering educational lectures and consultancy. KS's institution has received grants from/has funding arrangements with GSK for projects outside of this study.

Patient consent Completion of the questionnaire was considered as consent, as confirmed by the research ethics committee review. Consent was not sought for the 
case note review-only members of the usual clinical care team had access to identifiable information.

Ethics approval The study was approved by the South Humber research ethics committee.

Contributors RG, GK, CJNL, MN, JDR, RM, CS and IF were local collaborators and coordinated data collection in the sites. SCW carried out the analysis with input from $\mathrm{MJ}$ and $\mathrm{KS}$. All authors contributed to the design and interpretation of the analysis and made substantive contributions to the final version of the manuscript.

Provenance and peer review Not commissioned; externally peer reviewed.

\section{REFERENCES}

1. Salisbury DM. (Not) warts and all. Government fully considered HPV vaccine. BMJ 2008;337:a2552.

2. Jit M, Choi YH, Edmunds WJ. Economic evaluation of human papillomavirus vaccination in the United Kingdom. BMJ 2008;337:a769

3. Munoz N, Bosch FX, de Sanjose S, et al. Epidemiologic classification of human papillomavirus types associated with cervical cancer. N Engl J Med 2003;348:518-27.

4. Howell-Jones R, Bailey A, Beddows S, et al. Multi-site study of HPV type-specific prevalence in women with cervical cancer, intraepithelial neoplasia and normal cytology, in England. Br J Cancer 2010;103:209-16.

5. Dillner J, Kjaer SK, Wheeler CM, et al. Four year efficacy of prophylactic human papillomavirus quadrivalent vaccine against low grade cervical, vulvar, and vaginal intraepithelial neoplasia and anogenital warts: randomised controlled trial. BMJ 2010;341:c3493.

6. Brown DR, Schroeder JM, Bryan JT, et al. Detection of multiple human papillomavirus types in Condylomata acuminata lesions from otherwise healthy and immunosuppressed patients. J Clin Microbiol 1999;37:3316-22.

7. Health Protection Agency STI Annual Data Tables. Table 2: Total number of STI diagnoses and other episodes of care seen at genitourinary medicine clinics, UK and England 2000-2009. http://www.hpa.org.uk/web/HPAweb\&HPAwebStandard/ HPAweb C/1203348026613 (accessed Aug 2010).

8. Woodhall SC, Lacey CJN, Wikstrom A, et al. European Guidelines (IUSTIMHO) on the management of anogenital warts. Poster presentation at the 25th International Papillomavirus Conference; 8-14 May 2009. Malmö, Sweden, 2009.

9. Desai S, Wetten S, Woodhall SC, et al. Genital warts and cost of care in England Sex Transm Infect 2011;87:464-8.

10. Choi YH, Jit M, Gay N, et al. Transmission dynamic modelling of the impact of human papillomavirus vaccination in the United Kingdom. Vaccine 2010;28:4091-102.

11. Fairley CK, Hocking JS, Gurrin LC, et al. Rapid decline in presentations of genita warts after the implementation of a national quadrivalent human papillomavirus vaccination programme for young women. Sex Transm Infect 2009;85:499-502.

12. Donovan B, Franklin N, Guy R, et al. Quadrivalent human papillomavirus vaccination and trends in genital warts in Australia: analysis of national sentinel surveillance data. Lancet Infect Dis 2011:11:39-44.

13. Woodhall S, Ramsey T, Cai $\mathrm{C}$, et al. Estimation of the impact of genital warts on health-related quality of life. Sex Transm Infect 2008;84:161-6.

14. Woodhall SC, Jit M, Cai $\mathrm{C}$, et al. Cost of treatment and QALYs lost due to genital warts: data for the economic evaluation of HPV vaccines in the United Kingdom. Sex Transm Dis 2009;36:515-21.

15. Hammond P. (Not) warts and all. BMJ 2008:337:a2186.

16. O'Mahony C. Government decision on national human papillomavirus vaccine programme is a sad day for sexual health. Sex Transm Infect 2008;84:251.

17. Euro0ol-a new facility for the measurement of health-related quality of life. The EuroOol Group. Health Policy 1990;16:199-208
18. Dolan P, Gudex C, Kind P, et al. The time trade-off method: results from a general population study. Health Econ 1996;5:141-54

19. Kind P, Dolan P, Gudex C, et al. Variations in population health status: results from a United Kingdom national questionnaire survey. BMJ 1998:316:736-41.

20. Curtis L. Unit costs of health and social care. 2009. http://www.pssru.ac.uk/uc/ uc2009contents.htm (accessed Jul 2010).

21. NHS. NHS electronic drug tariff. http://www.ppa.org.uk/ppa/edt intro.htm (accessed Aug 2010)

22. Joint Formulary Committee. British National Formulary. 59th edn. London: British Medical Association and Royal Pharmaceutical Society of Great Britain, 2010.

23. Pearce V, Grant A, Adams E. Technical document-Phase 1 methodology of the proposed integrated sexual health pricing and currencies for London. Community Sexual Health Services. London: Pathway Analytics, 2009

24. BASHH Standards for the Management of Sexually Transmitted Infections. London: British Association of Sexual Health and HIV, 2010. http://www.bashh.org/guidelines (accessed Aug 2010)

25. Mortensen GL. Long-term quality of life effects of genital warts-a follow-study. Dan Med Bull 2010:57:A4140.

26. Persson G, Dahlof LG, Krantz I. Physical and psychological effects of anogenita warts on female patients. Sex Transm Dis 1993:20:10-13.

27. Data from the GU Medicine Clinical Activity Dataset (GUMCAD). London: Health Protection Agency, 2010.

28. Myers $\mathbf{E}$, Green S, Lipkus I. Patient preferences for health states related to HPV infection: visual analogue scales versus time trade-off elicitation. Proceedings of the 21st International Papillomavirus Conference; 20-27 Feb 2004, Mexico City, Mexico, 2004.

29. Brown RE, Breugelmans JG, Theodoratou D, et al. Costs of detection and treatment of cervical cancer, cervical dysplasia and genital warts in the UK. Curr Med Res Opin 2006;22:663-70.

30. Marra C, Ogilvie G, Gastonguay L, et al. Patients with genital warts have a decreased quality of life. Sex Transm Dis 2009;36:258-60.

31. Winer RL, Kiviat NB, Hughes JP, et al. Development and duration of human papillomavirus lesions, after initial infection. J Infect Dis 2005;191:731-8.

32. Dee A, Howell F, O'Connor $\mathrm{C}$, et al. Determining the cost of genital warts: a study from Ireland. Sex Transm Infect 2009;85:402-3.

33. Langley PC, White DJ, Drake SM. The costs of treating external genital warts in England and Wales: a treatment pattern analysis. Int J STD AIDS 2004; 15:501-8.

34. Marra F, Ogilvie G, Colley L, et al. Epidemiology and costs associated with genital warts in Canada. Sex Transm Infect 2009;85:111-15.

35. Pirotta M, Stein AN, Conway EL, et al. Genital warts incidence and healthcare resource utilisation in Australia. Sex Transm Infect 2010:86:181-6.

36. Insinga RP, Dasbach EJ, Myers ER. The health and economic burden of genita warts in a set of private health plans in the United States. Clin Infect Dis 2003:36:1397-403.

37. Monsonego J, Breugelmans JG, Bouee S, et al. [Anogenital warts incidence, medical management and costs in women consulting gynaecologists in France]. Gynecol Obstet Fertil 2007;35:107-13 [in French].

38. Fiander A, Cohet C. for the PasQual Study Team. Psychosocial impact of HPV-related diseases in men in the UK: the PasOual study. Proceedings of Eurogin 2010 Conference; 17-20 Feb 2010, Monte Carlo, Monaco, 2010.

39. Fiander A, Cohet Cfor the PasQual Study Team. Psychosocial impact of HPV-related diseases in women in the UK: the PasQual study. Proceedings of Eurogin 2010 Conference; 17-20 Feb 2010, Monte Carlo, Monaco, 2010

40. Drolet M, Brisson M, Maunsell E, et al. Loss of quality of life associated with genita warts: a prospective 6-month study. Proceedings of Eurogin 2010 Conference 17-20 Feb 2010, Monte Carlo, Monaco, 2010.

41. Department of Health 2010-2011 National Tariff Information. London: Department of Health. http://data.gov.uk/dataset/payment-by-results-2010-11-national-tariffinformation (accessed Aug 2010). 